\title{
MIGRACIONES ESTUDIANTILES: UN ABORDAJE INTERDISCIPLINARIO DESDE LAS HISTORIAS DE VIDA
}

\section{María Cristina Belloc}

\section{Andrea Dupuy}

\section{Silvia Pérez}

\section{Universidad Nacional de Mar del Plata-Argentina}

Resumo: O presente trabalho constitui uma intenção interdisciplinar de reflexão sobre o uso e potencialidades da história de vida como fonte geradora de dados qualitativos. Elas proporcionam os dados necessários para vincular as práticas migratórias dos estudantes que ingressam na Universidade Nacional de Mar del Plata (Argentina) com suas representações profissionais e de consumo cultural enquanto orientadoras da tomada de decisões para empreender uma mobilidade urbano-territorial. Entendemos as representações como os modos nos quais os estudantes interpretam e pensam a realidade segundo a posição que ocupam neste espaço social e que funcionam como orientadoras de seus comportamentos. A instrumentação de histórias de vida nos possibilitará compreender como se constroem as representações, que conteúdos a conformam e que funções cumprem, através do modo em que os próprios migrantes vivem as condições objetivas e constroem o mundo pelo qual tem transcorrido seu ciclo de vida e que os tem levado, em determinado momento, à decisão de migrar.

Palavras-chave: consumo cultural, histórias de vida, práticas migratórias, representações estudantis.

\begin{abstract}
The present work sets up an interdisciplinary attempt of reflection about use and potentialities of life history as generative source of qualitative information. They give necessary information to connect migratory performances of students that enter into Mar del Plata's National University (Argentina) with their profesional representation and their cultural consumption as a guide to make decisions to begin on an urban territorial mobility. We understand the representation as the ways that students
\end{abstract}


know and think the reality according to the position they occupy in the social space and they work as a guide of their behavior. Life story instrumentation will give us the possibility to understand how the representations are built, which is their conformation and which functions they fulfill, through the way the migrant themselves live the objetive conditions and build the world in which their life cicles have been gone by and, in a specific moment, they have been led to the migrate's decision.

Keywords: cultural consumption, life story, migratory performances, students representations.

El objetivo del trabajo que hoy presentamos pretende destacar la potencialidad de la historia de vida como fuente generadora de datos cualitativos.

En primer lugar interesa señalar que, más allá de la variedad de usos que admite como instrumento metodológico ya sea como herramienta de verificación en el marco de procesos investigativos o por su riqueza heurística en la formulación de hipótesis, en el caso que nos ocupa su virtud reside en la potencialidad para generar información relevante para interpretar procesos de cambio desde la óptica de quienes viven dichos procesos. En segundo lugar, debemos aclarar que cuando hablamos de historias de vida nos referimos a entrevistas de historias de vida o relatos de vida, a los que se accede a través de "interacción conversacional” para diferenciarnos de quienes utilizan, además del testimonio oral, otro tipo de documentos personales. Utilizamos el concepto en su sentido más restringido. ${ }^{1}$

El uso de los relatos de vida se inscribe en el marco de un proyecto de investigación en curso en la UNMdP, denominado "Representaciones estudiantiles y prácticas migratorias” que, desde un abordaje interdisciplinario, pretende vincular las prácticas migratorias de los ingresantes a la Universidad Nacional de Mar del Plata en 1998 con sus representaciones profesionales y de consumo cultural como orientadoras de la toma de decisiones para emprender una movilidad urbano-territorial. Entendemos las representaciones como

\footnotetext{
1 Distinción que corresponde a la introducida por Denzin en 1970 entre Life History (estudio de casos clínicos que incluye el relato de vida) y Life Story (la historia de una vida - o relato de vida - tal como la persona que la vivió la relata).
} 
los modos en que los estudiantes interpretan y piensan la realidad según la posición que ocupan en el espacio social y que funcionan como orientadoras de sus comportamientos.

Esta perspectiva nos permite vincular las posiciones sociales con las disposiciones ("habitus" o "estrategias representativas") y las tomas de posición de los estudiantes migrantes.

La interpretación de sus prácticas a partir de lo que los estudiantes informan respecto a las razones por las que actúan y, al mismo tiempo, la identificación de las circunstancias que los constriñen y que ellos desconocen, exige el recurso a instrumentos metodológicos que saquen a la luz la subjetividad de los agentes. Y es en este punto donde la utilización de relatos de vida adquiere particular relevancia.

La vinculación entre los factores estructurales que determinan una posición social y las prácticas asociadas a las mismas se logra a partir de la organización del proyecto en dos etapas bien diferenciadas: en una primera instancia, de naturaleza descriptiva, se caracteriza al alumnado migrante de la Universidad Nacional de Mar del Plata a partir de variables socioeconómicas y sociodemográficas, mediante la utilización de datos cuantitativos obtenidos de fuentes de información secundaria. Dichos datos nos permiten establecer la composición de los estudiantes según la posición que ocupan en el espacio social o, parafraseando a Bourdieu, en la "estructura de distribución de los diferentes tipos de capital”. Esta primera etapa culmina con la identificación de las variables relevantes a partir de las cuales se construye una muestra teórica de informantes cuyas historias de vida nos proporcionarán los datos necesarios para el análisis interpretativo de sus prácticas migratorias. Sólo a través de la instrumentación de esta herramienta podremos comprender cómo se construyen las representaciones, qué contenidos las conforman y qué funciones cumplen, a través del modo en que los propios migrantes viven las condiciones objetivas y construyen el mundo por el que ha transcurrido su ciclo de vida y que los ha llevado, en determinado momento, a la decisión de migrar. La construcción de ese mundo es, en gran parte, imaginaria, por lo tanto, los sujetos no manifiestan explícitamente sus estrategias; en consecuencia, la pericia del entrevistador - a través de la pertinencia y oportunidad de las preguntas que formula en relación con sus 
objetivos y del clima generado durante la interacción - permitirá develar los significados ocultos, las representaciones, las aspiraciones. En este punto cabe aclarar que carece de significación la concordancia entre el relato y los hechos. ${ }^{2}$ Si la representación que el estudiantado migrante ha construido acerca de la ciudad de Mar del Plata no se corresponde con la realidad, es irrelevante, por aquello de que "si las situaciones son definidas como reales por los hombres, entonces son reales en sus consecuencias” (Thomas citado en Kimery, 1992, p. 146). Lo verdaderamente significativo es que esa representación - ajustada o no a la realidad - operó como móvil de su práctica, es decir, lo llevó a migrar.

Por ello insistimos en que no es relevante la concordancia entre representación y realidad, sino las significaciones atribuidas a las prácticas. Los datos subjetivos que proveen los actores (sus objetivos y sus recursos) aparecen como indicadores para reconstruir sus estrategias, son expresiones de esas estrategias. (Forni, 1992).

En síntesis, cada una de las etapas descriptas - al proveer distinto tipo de información - permitirá resolver los interrogantes planteados. Así, las aproximaciones cuantitativas proporcionan la descripción del universo de estudio, sus características sociodemográficas y distribución geográfica. Sin embargo (al no poder dar cuenta de las razones que llevan a los sujetos a emprender una movilidad territorial en una determinada dirección y no en otra, a elegir una determinada carrera y descartar otras (debemos echar mano a estrategias metodológicas de naturaleza cualitativa que permitan analizar el impacto de procesos de cambio en sus trayectorias vitales y determinar si las prácticas migratorias representan estrategias de cambio o estrategias de reproducción. Así entonces, acceder a esta información posibilitará la construcción de tipologías de trayectorias vitales a través de la vinculación de las condiciones objetivas, las representaciones, los particulares modos de ver y percibir el mundo, los sistemas de valores - develados por el discurso - y las tomas de posición de

\footnotetext{
2 Aspecto en el que coincidimos con Saltalamacchia (1992, p. 34) cuando expresa “... el dato nunca es y nunca podrá ser lo real mismo. En tanto material simbólico el dato es siempre una determinada estructuración de la realidad, la transposición de lo real a lo simbólico siempre representa un proceso de reducción, de síntesis y de atribución de sentido, en tanto dato, lo real es siempre un real construido”.
} 
los sujetos. En este sentido, la historia de vida más que un fin en sí mismo, es un recurso que pretende dar cuenta de un fenómeno social - la migración de estudiantes universitarios hacia la ciudad de Mar del Plata - cuya magnitud se ha mantenido constante en los últimos 15 años.

Decíamos al comienzo que el objetivo principal de nuestro proyecto consiste en analizar relacionalmente los procesos simbólicos (representaciones) con las prácticas de los agentes. Para ello pretendemos aportar el modo singular en que cada agente responde al constreñimiento que sobre él ejerce la estructura social, incorporando su intencionalidad a través de las mediaciones del hábitus. Para este abordaje las herramientas conceptuales de Pierre Bourdieu (1984, 1988, 1991, 1996, 1997), “campo”, “posición social”, “hábitus" y "prácticas" nos permiten analizar el modo en que los sujetos interiorizan las estructuras sociales con el fin de comprender el sentido que otorgan a sus prácticas migratorias. A partir de este enfoque recuperamos al sujeto como productor de sus prácticas y abordamos la realidad mediante la articulación de "lo individual y lo social, de las estructuras internas de la subjetividad y las estructuras sociales externas” (Accardo, A.; Corcuff, P. citado en Gutiérrez, 1995, p. 64).

Esta perspectiva nos libera tanto de las corrientes que enfatizan el peso de la estructura sobre los actores, como de aquéllas que destacan el protagonismo abierto del sentido de su acción (Objetivismo/subjetivismo). Complementariamente, nos permite realizar un abordaje interdisciplinario de las prácticas sociales sin caer en el reduccionismo que sólo toma en cuenta la historia pasada del individuo, despojándolo de la historia social que lo convierte en agente.

Asimismo, cabe destacar que cuando hablamos de incorporar la intencionalidad no lo hacemos desde los intereses subjetivos o conscientes de los que el sujeto pueda dar cuenta o que pueda explicitar como móvil de sus prácticas, sino desde los intereses objetivos producto de la posición social que éste ocupa. $^{3}$

3 “La intencionalidad sin intención”, en términos de Wacquant (Bourdieu; Wacquant, 1995, p. 26). 
La mediación del habitus es, justamente, la que crea la ilusión de un ajuste entre las condiciones objetivas (las posibilidades de acceso a determinados bienes: una carrera universitaria, una determinada ciudad) y las esperanzas y representaciones de los sujetos (compatibles con esas condiciones).

Efectivamente, es esta mediación la que hace aparecer a las acciones humanas como si estuvieran orientadas intencionalmente hacia un fin, cuando, en realidad obedecen a disposiciones adquiridas, interiorizadas a lo largo de la trayectoria vital. Así entonces, los relatos de vida contribuyen a desentrañar las representaciones asociadas a condiciones objetivas (favorables o no), representaciones que reflejan el peso otorgado a la educación en el marco de las estrategias "posibles”, justamente "pensadas” por ser “probables” (ajustadas a condiciones objetivas). Nos posibilita acceder a los habitus desde los cuales la oferta educativa de la UNMdP y la oferta de consumo cultural de la ciudad es percibida y evaluada como "posible" por los estudiantes potenciales. Esta perspectiva, decíamos, rescata al productor de las prácticas ya no como sujeto sino como agente socializado. Por ello abordamos el análisis de las prácticas migratorias de los estudiantes en términos de estrategias, es decir de prácticas acerca de las cuales los sujetos puedan dar razones, o, en términos bourdianos estrategias en defensa de los intereses vinculados a la posición social que se ocupa en el campo de juego específico. A través de las entrevistas de historia de vida - donde los estudiantes puedan explicitar sus puntos de vista, sus percepciones y representaciones, donde el investigador pueda interrogar al testimoniante acerca del sentido de sus comportamientos, acerca del lugar que cada acontecimiento, cada hecho vivido ocupa en la “estructura de relevancias” (podremos comprender si sus prácticas migratorias responden a estrategias de cambio o a estrategias de reproducción).

En resumidas cuentas, una aproximación analítica que contextualiza los relatos de vida y, por ende, las trayectorias vitales, en la estructura de distribución de las condiciones objetivas en que los agentes están inmersos, nos redime de los reparos formulados por Bourdieu en relación con 
el método biográfico cuando afirma que tratar a "la vida como una historia... como un relato coherente... es sacrificarla a una ilusión retórica..." (Bourdieu, 1989, p. 29).

\section{La oralidad desde un abordaje interdisciplinario}

La variedad de corrientes de pensamiento que emplean las historias de vida no sólo al interior de una misma disciplina sino en campos disciplinares diferentes constituye la evidencia más clara de su relevancia como estrategia metodológica.

En el caso de la Antropología, ha constituido - y aún hoy constituye -un recurso insustituible para su práctica empírica. Asociada a la observación participante, representa - desde los orígenes de la disciplina - una de las herramientas básicas de su metodología del trabajo de campo.

En Sociología su uso se remonta a la Escuela Sociológica de Chicago cuya profusa producción - allá por los años 20 - reconoce al método biográfico un lugar destacado, si bien los investigadores chicagüenses reforzaron los testimonios orales con otro tipo de documentos personales.

Para el Psicoanálisis, que aparece a principios de siglo como modalidad de tratamiento de pacientes que padecen psíquicamente, el relato constituye la única forma de acceder a la historia del sujeto, representa la construcción simbólica de lo vivido por él.

La aplicación de fuentes orales en Historia es, en cambio, reciente, en razón del lugar secundario que la "historia oral” ha ocupado tradicionalmente en el ámbito historiográfico (a pesar de que los historiadores han usado testimonios orales desde la noche de los tiempos). ${ }^{4}$

\footnotetext{
4 Sin embargo los documentos usados tradicionalmente por los historiadores difieren sustancialmente de las historias orales debido a que no sólo no eran producidos a requerimiento de los historiadores, sino que consistían, normalmente, en autobiografías o memorias de personajes destacados.
} 
La historia del desarrollo de las ciencias sociales nos revela que cada una de ellas ha recurrido (con fluctuaciones según los criterios de cientificidad dominantes en cada época) al empleo de técnicas biográficas. Por ello cabe destacar que, más allá de las particularidades asociadas al objeto de estudio y al enfoque teórico adoptado, hay un interés común por rescatar la subjetividad de los agentes a partir del modo en que viven los hechos en los que participan.

La revitalización de las técnicas biográficas en el ámbito de Antropología y la Sociología a partir de los '60 y '70 respectivamente, y su uso sistemático en Historia - fines de los '70 y comienzos de los '80 -, se enmarcan en un contexto caracterizado por la crisis de los modelos macrosociales que al no poder dar cuenta de la emergencia de nuevos y complejos fenómenos sociales - llevaron al cuestionamiento de los grandes paradigmas científicos (en el sentido khuniano) que desechaban el análisis de la singularidad (el individuo, el caso único, el acontecimiento) para privilegiar el abordaje de las regularidades sociales, los comportamientos homogéneos (donde el hombre respondía a una racionalidad weberiana). “...lo que se ha puesto en duda ha sido la idea del progreso constante a través de una serie uniforme y predecible de etapas en las que, según se pensaba, los agentes sociales se ordenaban de acuerdo a solidaridades y conflictos que, en cierto sentido, estaban dados y eran inevitables”. (Levi, 1996, p. 120). Surge, de este modo, la necesidad de abordar las nuevas temáticas a partir de procedimientos analíticos originales y desde otra escala de observación, que en ningún modo implican la contradicción con lo social, sino “... un modo distinto de aproximarse a lo social; siguiendo el curso de un destino particular - el de un hombre o un grupo de hombres- a través de la multiplicación de los espacios y los tiempos, llegar a la madeja de relaciones donde éste se encontraba inscripto" (Revel, 1996, p. 146).

Después del mayo francés, las ciencias humanas como la Antropología con Polanyi, Geertz; la Historia con Paul Thompson, Giovanni Levi; la Sociología con Foucault; reducen su escala de análisis y diversifican su objeto de estudio, permitiendo el auge de los estudios microsociales que incluyen actores hasta ahora marginados de la escena científica: las mujeres, 
los campesinos, la clase obrera, los inmigrantes, la droga, la prostitución, la vejez, entre otros.

Ahora bien, específicamente en el ámbito historiográfico esta "nueva historia" 5 surge en oposición a la tradicional "historia rankiana" 6 incorporando temáticas hasta ese momento consideradas como carentes de historia: la familia (Henry, Laslett), la locura (Foucault), la femineidad (Joan Scott), el cuerpo (Roy Porter), la lectura (Robert Darton), las mentalidades (George Duby), ${ }^{7}$ el imaginario social (Jacques Le Goff). El nuevo enfoque se fundamenta en la consideración del carácter cultural de toda creación social. "El fundamento filosófico de la nueva historia es la idea de que la realidad está social o culturalmente constituida..." ${ }^{8}$ La historia deja de plantearse como el fiel reflejo de la realidad para comenzar a ser considerada como una representación de ella.

En este sentido, es destacable el aporte de los historiadores por rescatar las representaciones e imágenes de los individuos como modo de acceder a sus cosmovisiones. ${ }^{9}$ De esta forma, la preocupación por actividades humanas y personajes más diversificados, requiere la ampliación de las fuentes al poner de manifiesto, en ocasiones, la insuficiencia de los documentos escritos. Emerge, entonces, una fuente nueva y en ciertos casos, alternativa: "la historia oral”, es decir “... la historia escrita a partir de la evidencia recogida de una persona viva en vez de a partir de documentos escritos” (Prins, 1996, p. 144).

5 El término "nueva historia” (nouvelle histoire) fue acuñado en Francia como referencia a la obra del medievalista Jacques Le Goff, La Nouvelle histoire, donde el autor propone nuevos enfoques, problemas y objetos que vienen a replantear el "paradigma tradicional” (Burke, 1996).

6 Referida al historiador Leopold von Ranke (1715-1886) quien planteó los esquemas básicos de la historia tradicional, que debía basarse en forma exclusiva en documentos escritos. La historia auténtica era la historia de los "acontecimientos".

7 Cabe destacar que el término “mentalidad” fue acuñado por George Duby y Robert Mandrou. Esta línea surge como un intento de reconstrucción de los comportamientos, expresiones, silencios que traducen concepciones del mundo, las representaciones e imágenes a través de las cuales se identifican los grupos sociales y que constituyen el contenido básico de las psicologías colectivas.

8 Burke (1996, p. 15).

9 Dentro de esta nueva corriente de historiadores es Jacques Le Goff quien plantea el concepto de imaginario como una fuerza viva en toda sociedad, como "un fenómeno colectivo, social, histórico" (Le Goff, Nora, 1980). 
En este nuevo contexto la Antropología, la Sociología y el Psicoanálisis aparecen auxiliando a la Historia a través de su contribución teórica y metodológica. "El interés por toda la gama de la actividad humana los estimula a ser interdisciplinarios, en el sentido de aprender de antropólogos sociales, economistas, críticos literarios, psicólogos, sociólogos [...] y colaborar con ellos” (Burke, 1996, p. 19).

Debemos señalar que los testimonios orales complementan la información brindada por otras fuentes, de modo tal, que no sólo no las excluye, sino que constituyen una valiosa herramienta para comprender de modo más acabado la realidad a estudiar. "Las fuentes escritas y las orales no son mutuamente excluyentes. La historia oral como intrínsecamente diferente y por lo tanto específicamente útil” (Portelli, 1991, p. 37).

Como cada relato puede interpretarse desde una perspectiva vivencial de lo real, a través de la mirada etnográfica es posible acceder de modo directo a la interacción entre ese "yo" que relata y el mundo que nos interesa estudiar. Se puede acceder en el nivel simbólico, al mundo de las emociones, valores, representaciones y en el nivel concreto particular, al relato de la organización del yo, de situaciones, proyectos y actos.

El abordaje interdisciplinario es de un valor inapreciable para la comprensión y decodificación del lenguaje del testimoniante, porque permite corregir los sesgos y parcialidades a través de lecturas múltiples y cruzadas.

La mirada psicoanalítica, a su vez, nos permite dar cuenta de la singularidad del sujeto a través su discurso. En este contexto, la "cura por la palabra” (expresión con que se denominaba a esta particular forma de abordar el tratamiento de enfermedades psíquicas) expresa la importancia del lenguaje para la exploración de fenómenos psíquicos inconscientes. Esta modalidad supone el encuentro de un analista con otro individuo que demanda ser escuchado a partir de una problemática y, en la medida en que deposita en el analista un saber sobre su sufrimiento, espera, de este modo, ser curado del mismo. Aquí se establece una primera diferencia entre el psicoanálisis como método terapéutico y la historia de vida como relato. En ésta también se produce el encuentro entre dos personas, pero el entrevistador es quien demanda le sean relatados determinados acontecimientos de la vida 
del entrevistado, quien, por su parte, no tiene por que suponerle un saber al entrevistador.

A diferencia de la ciencia que se ocupa de universales, de lo medible, cuantificable y que utiliza preferencialmente metodologías cuantitativas, el psicoanálisis trabaja con lo forcluido de la ciencia, con el residuo de la misma, que es el sujeto en su particularidad. Este sujeto, rechazado por la ciencia, lleva a Lacan a sostener que ésta es un discurso sin sujeto. Como teoría, el psicoanálisis da cuenta de la estructuración psíquica del sujeto a través del análisis del lenguaje. ${ }^{10}$ "El relato es la modalidad de la palabra en la que se articula una zona de otro modo inaccesible de la experiencia y en la que figura la especificidad de las relaciones que el sujeto mantiene con el lenguaje, con su historia... El relato constituye para el psicoanálisis su único vehículo y su principal herramienta.” (Kaufmann, 1992, p. 676).

El axioma de la mitología cristiana "en el principio fue el verbo", ubica a la palabra en los orígenes de la humanidad, aproximándose al planteo de Lacan cuando afirma que "sólo es posible dar cuenta del ser del sujeto en y por la palabra, en relación con el deseo inconsciente”. Lacan sostiene que el hombre es un ser de lenguaje y que éste precede al sujeto.

Tanto en historias de vida como en la consulta analítica, el instrumento a utilizar es la entrevista y, en ambos casos se podría pensar que quien escucha funciona como lector del texto enunciado por el entrevistado. De esta manera, el analista o entrevistador (según sea el caso) con su escucha, ofrece ese texto a la posibilidad de una lectura diferente. Es el tratamiento que Freud, por ejemplo, dio a los sueños, como escrituras jeroglíficas a descifrar.

${ }^{10}$ El lenguaje es un sistema de signos en oposición, de modo tal que un significante dentro de una cadena significante, sólo cobra sentido en relación con los demás. En un discurso, un significante sólo cobra sentido apres-coup, a posteriori, puesto que el último significante otorga el sentido, por el apres-coup. La producción de sentido tiene lugar sin que el significado sea tomado en cuenta, se produce por el abrochamiento de un significante a un significante. 
Asimismo, la posibilidad de leer algo de lo no dicho en el discurso manifiesto del sujeto se relaciona con la definición del inconsciente ${ }^{11}$ "estructurado como lenguaje”, que no se encuentra en las profundidades del ser, sino que se expresa a través de un lenguaje, de un sueño, un acto fallido, un lapsus, en la superficie del discurso. Estas operaciones fallidas son consideradas actos psíquicos que tienen un sentido y significado que es posible develar. Por ello, a través de lo manifestado por los entrevistados - por aquello de que los sujetos dicen más de lo que saben que dicen- se intentará advertir en el análisis de las entrevistas algo de dicho saber no reconocido por la conciencia, un más allá de la lógica de la razón, en relación con el deseo inconsciente y los ideales.

Cabe aclarar que si bien la teoría psicoanalítica no habla de historias de vida, Lacan - retomando a Freud - predica que la reconstitución completa de la historia del sujeto es el elemento esencial constitutivo, estructural de progreso analítico. Para Freud siempre se trata de la aprehensión de un caso singular. Lo que cuenta es la reintegración por parte del sujeto de su historia, entendida como el pasado historizado en el presente. Por ello no es en sí tan importante que el sujeto rememore los acontecimientos formadores de su existencia, sino lo que reconstruye de ellos. Se trata menos de recordar que de reescribir la historia.

\section{Referencias}

BOURDIEU, P. Los estudiantes y la cultura. Barcelona: Labor, 1969.

BOURDIEU, P. Cosas dichas. Buenos Aires: Gedisa, 1988.

BOURDIEU, P. La distinción. Buenos Aires: Taurus, 1988.

\footnotetext{
11 A partir del descubrimiento del inconsciente Freud subvierte el orden de la razón cartesiana - donde el sujeto es racional, pensante y consciente -, al sostener que estamos constituidos por dos instancias psíquicas: la conciencia y el inconsciente, siendo ésta la que comanda.
} 
BOURDIEU, P. Sociología y cultura. México: Grijalbo, 1990.

BOURDIEU, P. El sentido práctico. Madrid: Taurus, 1991.

BOURDIEU, P. Razones prácticas. Barcelona: Anagrama, 1997.

BOURDIEU, P. Capital cultural, escuela y espacio social. México: Siglo XXI, 1997.

BOURDIEU, P.; WACQUANT, L. Respuestas por una antropología reflexiva. México: Grijalbo, 1995.

BURKE, P. Obertura: la nueva historia, su pasado y su futuro. In: BURKE, P. Formas de hacer historia. Madrid: Alianza, 1996.

DUBY, G. Orientações da pesquisa historica na Franca, 1950-1980. In: DUBY, G. Idade Média, Idade dos homens. São Paulo: Schwartz, 1989.

FORNI, F. Estrategias de recolección y estrategias de análisis en la investigación social. In: FORNI, E.; GALLART, M. A.; VASILACHIS DE GIALDINO, I. Métodos cualitativos II: la práctica de la investigación. Buenos Aires: Centro Editor de A. Latina, 1992.

GUTIÉRREZ, A. Pierre Bourdieu. Posadas: Universidad Nacional de Misiones, 1995.

LE GOFF, J.; NORA, P. Hacer la historia. Barcelona: Laia, 1980.

PORTELLI, A. Lo que hace diferente a la historia oral. In: SCWARZSTEIN, D. (Comp.). La historia oral. Buenos Aires: Centro Editor, 1991.

PRINS, G. Historia oral. In: BURKE, P. Formas de hacer historia. Madrid: Alianza, 1996. 
REVEL, J. Microanálisis y construcción de lo social. Entrepasados, año V, n. 10, 1996.

SALTALAMACCHIA, H. La Historia de vida: reflexiones a partir de una experiencia de investigación. Costa Rica: Cijup, 1992.

THOMPSON, P. Historia de vida en el análisis del cambio social. In: MARINAS, J. M.; SANTAMARINA, C. (Comp.). La historia oral: métodos y experiencias. Ex. Libris, 1996. 